\title{
Alcohol Drinking, Cigarette Smoking and Risk of Colorectal Cancer in the Korean Multi-center Cancer Cohort
}

\section{Sooyoung Cho ${ }^{1}$, Aesun Shin ${ }^{1}$, Sue K. Park ${ }^{1,2,3}$, Hai-Rim Shin ${ }^{4}$, Soung-Hoon Chang ${ }^{5}$, Keun-Young Yoo ${ }^{1}$}

Departments of ${ }^{1}$ Preventive Medicine and ${ }^{2}$ Biomedical Science, Seoul National University College of Medicine, ${ }^{3}$ Cancer Research Center, Seoul National University, Seoul, Korea, ${ }^{4}$ World Health Organization Regional Office for the Western Pacific, Manila, Philippines, ${ }^{5}$ Department of Preventive Medicine, Konkuk University School of Medicine, Chungju, Korea

Background: The present study aimed to examine the association between cigarette smoking, alcohol consumption and colorectal cancer risk among Korean adults.

Methods: Data from the Korean Multi-center Cancer Cohort between 1993 and 2005 were analyzed. The study population comprised 18,707 subjects aged older than 20 years old. The subjects were followed until December 31, 2011 (median follow-up of 11.2 years). The Cox proportional hazard model was used to estimate the hazard ratio (HR) and 95\% confidence intervals of cigarette smoking and alcohol consumption for colorectal cancer risk.

Results: In men, longer duration and higher average amount of alcohol consumption were associated with elevated risk of colorectal cancer (HR 1.93 [1.17-3.18] for $\geq 30$ years of consumption compared to non-drinkers; HR 2.24 [1.31-3.84] for $\geq 30 \mathrm{~g} / \mathrm{d}$ ). Former smokers showed a non-significantly elevated risk of colorectal cancer in men. There was no apparent association between alcohol consumption or cigarette smoking and colorectal cancer risk among women.

Conclusions: Alcohol consumption was associated with increased colorectal cancer risk among Korean men, and both a longer duration and a higher amount of consumption were associated with elevated risk.

(J Cancer Prev 2015;20:147-152)

Key Words: Colorectal neoplasms, Smoking, Alcohol drinking, Prospective studies

\section{INTRODUCTION}

Colorectal cancer is the third most common cancer in men and the second most common cancer in women worldwide. ${ }^{1}$ In Korea, colorectal cancer incidence has increased during the last decade, with an annual percentage change of $5.6 \%$ (6.1\% in males and $4.5 \%$ in females) from 1999 to 2011 in age-adjusted rates. ${ }^{2}$

Alcohol consumption and cigarette smoking are regarded as major risk factors for gastrointestinal cancer, including colorectal cancer. ${ }^{3}$ Alcohol is a group 1 carcinogen with sufficient evidence for colorectal cancer, ${ }^{4}$ and the World Cancer Research Fund/ American Institute of Cancer Research suggests that elevated risk of colorectal cancer caused by excessive alcohol consumption (more than approximately $30 \mathrm{~g}$ per day of ethanol) is 'convincing' for men but probable for women. ${ }^{5}$ As a result of cumulative evidence from epidemiological studies, colorectal cancer has been listed as a cancer site with 'sufficient evidence' for human linked to group 1 carcinogen cigarette smoking. ${ }^{4.6-10}$

However, epidemiological studies conducted in Korea have not shown a significant relationship between those risk factors, smoking $^{11}$ and alcohol ${ }^{12-15}$ and colorectal cancer risk. To elucidate these discrepancies, we examined the association between cigarette smoking, alcohol consumption and colorectal cancer risk in a Korean cohort study.

Received May 21, 2015, Revised June 8, 2015, Accepted June 8, 2015

Correspondence to: Aesun Shin

Department of Preventive Medicine, Seoul National University College of Medicine,103 Daehak-ro, Jongno-gu, Seoul 110-799, Korea Tel: +82-2-740-8331, Fax: +82-2-747-4830, E-mail: shinaesun@snu.ac.kr, ORCID: Aesun Shin, http://orcid.org/0000-0002-6426-1969

Copyright (C) 2015 Korean Society of Cancer Prevention

(c) This is an Open Access article distributed under the terms of the Creative Commons Attribution Non-Commercial License (http://creativecommons.org/licenses/by-nc/4.0) which permits unrestricted non-commercial use, distribution, and reproduction in any medium, provided the original work is properly cited. 


\section{MATERIALS AND METHODS}

\section{Study population}

The Korean Multi-center Cancer Cohort is a population-based prospective cohort designed to investigate the relationship between exposures to environmental factors, lifestyle factors, host factors and the risk of cancer in Korea. ${ }^{16}$ From 1993 to 2005 , a total of 19,252 participants ( 7,727 men and 11,525 women) were recruited. We excluded those who were younger than 20 years old (164 men and 341 women), who had no information about both cigarette smoking and alcohol consumption (65 men and 130 women), with a prior diagnosis of colorectal cancer ( 9 men and 19 women), or who were censored within one month from the baseline survey ( 2 men and 3 women). Finally, 18,522 participants (7,488 men and 11,034 women) were included in the final analysis. This study approved by the Institutional Review Board (IRB) at Seoul National University Hospital (IRB number 1407-097-597)

\section{Exposure, covariate, and outcome assessment}

Data on smoking habits, alcohol consumption, and other lifestyle factors were collected by direct interview at baseline. ${ }^{16}$ Participants were asked to answer questions of whether they drank alcoholic beverages ("Yes", "Yes, but not now", or "No" were the answer options to the question, "Have you ever drunk alcohol?"), and for "ever drinkers", consumption frequency and average quantity of one serving over the past year by beverage type was recorded. For cigarette smoking, cigarette-smoking habits ("Have you smoked more than 400 cigarettes during your entire life?"), smoking duration, average number of cigarettes smoked per day were asked. Cohort subjects were followed for cancer occurrence by using the Korea Central Cancer Registry database and for death by linking death certificated database of the Statistics Korea until December 31, 2011.

\section{Statistical analysis}

We used Cox proportional hazards model with age as the time scale to estimate multivariate-adjusted hazard ratios (HRs) and 95\% confidence intervals (CIs). ${ }^{17,18}$ Due to substantial differences in smoking and alcohol use habits between men and women, all analyses were stratified by sex. All statistical analyses were performed by using SAS software version 9.4 (SAS Institute Inc., Cary, NC, USA).
Table 1. General characteristics of the study subjects

\begin{tabular}{|c|c|c|c|}
\hline Variable & Men & Women & Total \\
\hline Total case & 7,488 & 11,034 & 18,522 \\
\hline Colorectal cancer case & $112(1.5)$ & $108(1.0)$ & $220(1.2)$ \\
\hline \multicolumn{4}{|l|}{ Age at baseline (yr) } \\
\hline $20-29$ & $349(4.7)$ & $322(2.9)$ & $671(3.6)$ \\
\hline $30-39$ & $830(11.1)$ & $1,096(9.9)$ & $1,926(10.4)$ \\
\hline $40-49$ & $1,356(18.1)$ & $2,080(18.9)$ & $3,436(18.6)$ \\
\hline $50-59$ & $1,834(24.5)$ & $3,016(27.3)$ & $4,850(26.2)$ \\
\hline $60-69$ & $2,173(29.0)$ & $3,242(29.4)$ & $5,415(29.2)$ \\
\hline $70-79$ & $851(11.4)$ & $1,142(10.3)$ & $1,993(10.8)$ \\
\hline $80-89$ & $91(1.2)$ & $133(1.2)$ & $224(1.2)$ \\
\hline$\geq 90$ & $4(0.1)$ & $3(0.0)$ & $7(0.0)$ \\
\hline \multicolumn{4}{|l|}{ Education level (yr) } \\
\hline Uneducated & $880(11.8)$ & $3,203(29.0)$ & $4,083(22.0)$ \\
\hline $1-12$ & $6,133(81.9)$ & $7,603(68.9)$ & $13,736(74.2)$ \\
\hline$\geq 13$ & $422(5.6)$ & $186(1.7)$ & $608(3.3)$ \\
\hline Missing & $53(0.7)$ & $42(0.4)$ & $95(0.5)$ \\
\hline \multicolumn{4}{|c|}{ Total time of moderate physical activity (h/wk) } \\
\hline Never & $1,536(20.5)$ & $1,357(12.3)$ & $2,893(15.6)$ \\
\hline $0.5-7$ & $2,010(26.8)$ & $3.149(28.5)$ & $5,159(27.9)$ \\
\hline$\geq 7$ & $1,736(23.2)$ & $3,009(27.3)$ & $4,745(25.6)$ \\
\hline Missing & $2,206(29.5)$ & $3.519(31.9)$ & 5,725 (30.9) \\
\hline \multicolumn{4}{|c|}{ Body mass index $\left(\mathrm{kg} / \mathrm{m}^{2}\right)$} \\
\hline$<18.5$ & $336(4.5)$ & $381(3.5)$ & 717 (3.9) \\
\hline $18.5-22$ & $3,215(42.9)$ & $3.773(34.2)$ & $6,988 \quad(37.7)$ \\
\hline $23-24$ & $1,692(22.6)$ & $2,459(22.3)$ & $4,151 \quad(22.4)$ \\
\hline$\geq 25$ & $1,796(24.0)$ & $3.703(33.6)$ & $5,499(29.7)$ \\
\hline Missing & $449(6.0)$ & $718(6.5)$ & $1,167(6.3)$ \\
\hline
\end{tabular}

Values are presented as number only or number (\%).

\section{RESULTS}

The general characteristics of study participants are shown in Table 1. More than half of participants were 50 to 69 years old at baseline (26.2\% ages 50 to 59 years and $29.2 \%$ ages 60 to 69 years). The majority of men were current drinkers (64.5\%), and most women were non-drinkers $(78.5 \%)$. Moderate (10 to $29 \mathrm{~g}$ of alcohol per day) and heavy drinkers (more than $30 \mathrm{~g}$ of alcohol per day) was $17.1 \%$ and $23.0 \%$ in men, compared to $2.4 \%$ and $1.4 \%$ in women, respectively.

During a median 11.2 years of follow-up and 21.0 million person-years of observation, there were 220 colorectal cancer cases (112 men and 108 women). The age-specific incident rates of the study participants were comparable to those of Korean population (average annual incidence from 2003 to 2007) published in Cancer Incidence in Five Continents Volume X (data are not shown.). ${ }^{19}$ The HRs and 95\% CIs for colorectal cancer according to alcohol consumption are shown by sex in Table 2 . The $31.5 \%$ of men had drunk alcohol for more than 30 years, whereas only $2.5 \%$ of women did. The Table 2 shows that current 
male drinkers had a $70 \%$ increased risk of developing colorectal cancer (HR 1.70, 95\% CI 1.05-2.76) compared to non-drinkers). Both longer duration and higher average amount of alcohol consumption were associated with elevated risk for colorectal cancer (HR 1.93, 95\% CI 1.17-3.18 for $\geq 30$ years of consumption compared to non-drinkers; HR 2.24, 95\% CI 1.31-3.84 for $\geq 30$ $\mathrm{g} / \mathrm{d})$. In contrast, there was no association between alcohol consumption and colorectal cancer incidence in women nor was

Table 2. HRs and 95\% CIs for colorectal cancer according to alcohol consumption in the Korean Multi-center Cancer Cohort, 1993-2005

\begin{tabular}{|c|c|c|c|c|c|c|c|c|}
\hline & \multicolumn{4}{|c|}{ Men } & \multicolumn{4}{|c|}{ Women } \\
\hline & Number (\%) & Person-year & $\begin{array}{c}\text { Colorectal } \\
\text { cancer } \\
\text { case }(\mathrm{n})\end{array}$ & $\operatorname{HR}(95 \% C I)^{a}$ & Number (\%) & Person-year & $\begin{array}{l}\text { Colorectal } \\
\text { cancer } \\
\text { case }(\mathrm{n})\end{array}$ & $\operatorname{HR}(95 \% \mathrm{CI})^{\mathrm{a}}$ \\
\hline \multicolumn{9}{|c|}{ Alcohol consumption history } \\
\hline Never drinker & $1,845(24.6)$ & $20,102.6$ & 22 & ref. & $8,660(78.5)$ & $103,189.0$ & 90 & Ref. \\
\hline Former drinker & $783(10.5)$ & $7,880.6$ & 10 & $0.92(0.43-1.96)$ & $234(2.1)$ & $2,452.1$ & 3 & $1.29(0.40-4.16)$ \\
\hline Current drinker & $4,827(64.5)$ & $51,650.7$ & 79 & $1.70(1.05-2.76)$ & $2,072(18.8)$ & $23,413.3$ & 15 & $0.85(0.49-1.47)$ \\
\hline Missing & $33(0.4)$ & 345.8 & 1 & $2.08(0.28-15.71)$ & $68(0.6)$ & 737.1 & 0 & \\
\hline \multicolumn{9}{|c|}{ Duration of alcohol consumption (yr) } \\
\hline Never drinker & $1,845(24.6)$ & $20,102.6$ & 22 & ref. & $8,660(78.5)$ & $103,189.0$ & 90 & Ref. \\
\hline$<15$ & 704 (9.4) & $8,016.2$ & 1 & $0.31 \quad(0.04-2.27)$ & $975(8.8)$ & $11,339.2$ & 8 & $1.09(0.53-2.26)$ \\
\hline $15-29$ & $2,111 \quad(28.2)$ & 23.552 .6 & 23 & $1.32(0.72-2.44)$ & $793(7.2)$ & $8,683.7$ & 7 & $0.96(0.44-2.08)$ \\
\hline$\geq 30$ & $2,377(31.7)$ & $23,129.3$ & 60 & $1.93(1.17-3.18)$ & $284(2.6)$ & $2,909.1$ & 1 & $0.33(0.05-2.34)$ \\
\hline Missing & $451 \quad(6.0)$ & $5,179.1$ & 6 & $0.99(0.40-2.46)$ & $322(2.9)$ & 3.670 .5 & 2 & $0.67(0.16-2.74)$ \\
\hline \multicolumn{9}{|c|}{ Alcohol consumption amount (g/d) } \\
\hline Never drinker & $1,845(24.6)$ & $20,102.6$ & 22 & ref. & $8,660(78.5)$ & $103,189.0$ & 90 & Ref. \\
\hline$<10$ & $1,823(24.3)$ & $19,271.4$ & 24 & $1.28(0.71-2.31)$ & $1,408(12.8)$ & $14,953.8$ & 9 & $0.82(0.41-1.63)$ \\
\hline $10-29$ & $1,282(17.1)$ & $13,115.5$ & 20 & $1.77(0.96-3.26)$ & $264(2.4)$ & $2,792.1$ & 2 & $0.95(0.23-3.87)$ \\
\hline$\geq 30$ & $1,723(23.0)$ & $17,270.9$ & 38 & $2.24(1.31-3.84)$ & $151(1.4)$ & $1,666.3$ & 1 & $0.76(0.11-5.44)$ \\
\hline Missing & 815 (10.9) & $10,219.4$ & 8 & $0.77(0.34-1.75)$ & $551(5.0)$ & $7,190.3$ & 6 & $0.97(0.42-2.24)$ \\
\hline
\end{tabular}

HR, Hazard ratio; CI, confidence interval; Ref., reference. ${ }^{a}$ Adjusted for body mass index $\left(\mathrm{kg} / \mathrm{m}^{2} ;<18.5,18.5-22,23-24, \geq 25\right)$, moderate physical activity ( $\mathrm{h} / \mathrm{wk}$; never, $0.5-6, \geq 7$ ), and cigarette smoking history (never smoker, former smoker, current smoker).

Table 3. HRs and $95 \%$ CIs for colorectal cancer according to cigarette smoking in the Korean Multi-center Cancer Cohort, 1993-2005

\begin{tabular}{|c|c|c|c|c|c|c|c|c|}
\hline & \multicolumn{4}{|c|}{ Men } & \multicolumn{4}{|c|}{ Women } \\
\hline & Number (\%) & Person-year & $\begin{array}{c}\text { Colorectal } \\
\text { cancer } \\
\text { case }(\mathrm{n})\end{array}$ & HR $(95 \% C I)^{a}$ & Number (\%) & Person-year & $\begin{array}{l}\text { Colorectal } \\
\text { cancer } \\
\text { case }(\mathrm{n})\end{array}$ & $\mathrm{HR}(95 \% \mathrm{CI})^{\mathrm{a}}$ \\
\hline \multicolumn{9}{|c|}{ Cigarette smoking history } \\
\hline Never smoker & $1,486(19.8)$ & $16,624.2$ & 21 & ref. & $10,018(90.8)$ & $118,501.0$ & 102 & Ref. \\
\hline Former smoker & $1,714(22.9)$ & $16,538.6$ & 34 & $1.33(0.76-2.32)$ & $208(1.9)$ & $2,138.7$ & 3 & $1.14(0.35-3.67)$ \\
\hline Current smoker & $4,280(57.2)$ & $46,733.7$ & 57 & $0.97(0.58-1.62)$ & $761(6.9)$ & $8,618.5$ & 3 & $0.30(0.10-0.97$ \\
\hline Missing & $8(0.1)$ & 83.3 & 0 & & $47(0.4)$ & 533.0 & 0 & \\
\hline \multicolumn{9}{|c|}{ Smoking duration (yr) } \\
\hline Never smoker & $1,486(19.8)$ & $16,624.2$ & 21 & ref. & $10,018(90.8)$ & $118,501.0$ & 102 & Ref. \\
\hline$<20$ & $1,200(16.0)$ & $12,908.6$ & 7 & $1.04(0.43-2.48)$ & $295(2.7)$ & 3.399 .0 & 1 & $0.33(0.05-2.35$ \\
\hline $20-39$ & $2,259(30.2)$ & $24,596.6$ & 34 & $1.05(0.60-1.85)$ & $340(3.1)$ & $3,661.6$ & 1 & $0.22(0.03-1.62$ \\
\hline$\geq 40$ & $1,606(21.4)$ & $14,479.2$ & 31 & $1.00(0.56-1.78)$ & $162(1.5)$ & $1,607.9$ & 1 & $0.46(0.06-3.35$ \\
\hline Missing & $937(12.5)$ & $11,371.2$ & 19 & $1.37(0.68-2.74)$ & $219(2.0)$ & $2,621.8$ & 3 & $0.93(0.29-2.97)$ \\
\hline \multicolumn{9}{|c|}{ Lifetime cigarette smoking (pack-year) } \\
\hline Never smoker & $1,486(19.8)$ & $16,624.2$ & 21 & ref. & $10,018(90.8)$ & $118,501.0$ & 102 & Ref. \\
\hline$<10$ & $841(11.2)$ & $8,659.0$ & 13 & $2.04(1.01-4.14)$ & $360(3.3)$ & $3,970.7$ & 1 & $0.25(0.04-1.83$ \\
\hline $10-19$ & $1,022(13.6)$ & $10,542.0$ & 8 & $0.76(0.33-1.74)$ & $207(1.9)$ & $2,223.7$ & 1 & $0.38(0.05-2.77)$ \\
\hline$\geq 20$ & $3,095(41.3)$ & $31,567.6$ & 49 & $0.95(0.56-1.60)$ & $200(1.8)$ & $2,179.0$ & 1 & $0.38(0.05-2.76$ \\
\hline Missing & $1,044(13.9)$ & $12,586.9$ & 21 & $1.34(0.68-2.63)$ & $249(2.3)$ & $2,916.8$ & 3 & $0.80(0.25-2.57)$ \\
\hline
\end{tabular}

HR, Hazard ratio; CI, confidence interval; Ref., reference. ${ }^{a}$ Adjusted for body mass index $\left(\mathrm{kg} / \mathrm{m}^{2}\right.$; $\left.<18.5,18.5-22,23-24, \geq 25\right)$, moderate physical activity (h/wk; never, 0.5-6, $\geq 7$ ), and alcohol consumption history (never drinker, former drinker, current drinker). 
there statistical significance.

The HRs and 95\% CIs for colorectal cancer according to cigarette smoking are shown by sex in Table 3 . Former smokers comprised $22.7 \%$ and current smokers comprised $56.7 \%$ in men, whereas $89.7 \%$ of women were non-smokers. Most male smokers (including former and current smokers) had smoked more than 20 pack-years in their lifetime, whereas most female smokers smoked 10 to 19 pack-years in their lifetime. Male former smokers showed a non-significantly elevated risk for colorectal cancer. Men who smoked less than 10 pack-years had a significantly higher risk for colorectal cancer. Smoking status and amount of lifetime cigarette smoking did not show a significant relationship with colorectal cancer in women. Smoking duration was not significantly related to colorectal cancer regardless of sex.

\section{DISCUSSION}

In this study, we analyzed the association between cigarette smoking, alcohol consumption and colorectal cancer risk among Korean adults. Both longer duration and high alcohol consumption amount were related to an increased risk of colorectal cancer in men. Male former smokers also showed an elevated colorectal cancer risk. In contrast, no apparent relationship between these risk factors and colorectal cancer were observed among women.

A hospital-based case-control study conducted in Korea showed an elevated risk of colorectal cancer only among heavy drinkers whose alcohol consumption was $30 \mathrm{~g} / \mathrm{d}$ or more. ${ }^{12} \mathrm{~A}$ health insurance-based cohort study also reported an elevated risk of distal colon and rectal cancer among men with frequent alcohol consumption (3-4 times/wk) or high average consumption amount or more than one bottle of Korean distilled spirits. ${ }^{20}$ These results are consistent with our results. However, other Korean studies report no significant association ${ }^{14}$ or difference in risk by sub-sites. ${ }^{12.21}$

A meta-analysis with 57 articles published between 1986 and 2010 showed a higher risk of colorectal cancer among heavy drinkers, ${ }^{22}$ and these elevated risks were more prominent in men than women and Asians rather than Europeans or North Americans. ${ }^{22}$ A meta-analysis of 16 prospective cohort studies showed a stronger association with rectal cancer than colon cancer risk, and the association was significant only among men (for rectal cancer, HR 1.64, 95\% CI 1.39-1.93; for colon cancer, HR $1.79,95 \% \mathrm{CI} 1.38-2.33) .^{23} \mathrm{~A}$ pooled analysis of 8 cohort studies from North America and Europe reported a significant risk only among the highest consumption group and the elevated risk was more significant for distal colon and rectal cancer. ${ }^{24} \mathrm{~A}$ pooled analysis of five cohort studies conducted in Japan showed a significant association between alcohol consumption level and colorectal cancer risk in both sexes and all sub-sites of the colorectum. ${ }^{25}$ Our results, in addition to those of another report ${ }^{22,24}$ that did not find significantly elevated risk of colorectal cancer among light drinkers, are consistent with a recent meta-analysis. ${ }^{26}$

In regard to cigarette smoking and colorectal cancer risk, previous epidemiological studies conducted in Korea did not find clear associations. ${ }^{1520.27}$ In a case-control study of men, none of the smoking variables, such as cigarette smoking history, duration of smoking, number of cigarettes per day, and age at start of smoking, were associated with colorectal cancer risk. ${ }^{15} \mathrm{~A}$ health insurance-based cohort study did not find any association between smoking and colorectal cancer in both men and women. ${ }^{27}$ However, the most recent health insurance-based cohort study suggested marginal elevated risk for distal colon and rectal cancer among male former smokers. ${ }^{20}$ In a Korean cohort study with an elderly population, former smokers showed a higher risk of colorectal cancer. ${ }^{11}$ However, longer duration of smoking of 45 years and more was significantly associated with elevated risk, whereas higher pack-year was not associated with the risk. ${ }^{11}$

In a meta-analysis, a stronger association with colorectal cancer risk was observed in former smokers than current smokers. ${ }^{28.30}$ The pooled relative risk in former smokers was 1.17 (95\% CI 1.11-1.22), whereas that for current smokers was 1.07 (95\% CI 0.99-1.16). ${ }^{28}$ In another meta-analysis by sub-sites, the association was stronger for rectal cancer than colon cancer. ${ }^{29}$ Similar to our results, the European Prospective Investigation into Cancer and Nutrition study showed significantly elevated risk of colorectal cancer only among former smokers but not among current smokers. However, the association was most prominent for proximal colon cancer.

We did not find an association between cigarette smoking and colorectal cancer risk among women. Less than $10 \%$ of women were 'ever smokers' in our study; therefore, statistical power was not adequate. A Norwegian cohort study suggested higher susceptibility for colorectal cancer among women; however, that study included more female smokers than our study. ${ }^{31}$

The strengths of our study include prospective study design, which clarifies the temporal association between exposures to risk factors and colorectal cancer occurrence. Outcome ascertainment via linkage to cancer registries and a death certificate database minimized follow-up loss.

A limitation of the study includes lack of replicate information on alcohol consumption and cigarette smoking habits, which may 
change after the baseline survey. Although the median follow-up time was longer than 10 years, we do not have enough statistical power to analyze the data according to the sub-sites of colorectal cancer or former/current smoking/drinking status. Additionally, information on the duration of quitting smoking and exposure to secondhand smoke was not available.

Alcohol consumption was associated with increased colorectal cancer risk among Korean men, and both longer duration and higher amount of consumption were associated with elevated risk.

\section{ACKNOWLEDGMENTS}

This work was supported by the Research Resettlement Fund for the new faculty of SNU (2013).

\section{CONFLICTS OF INTEREST}

No potential conflicts of interest were disclosed.

\section{REFERENCES}

1. Ferlay J, Soerjomataram I, Dikshit R, Eser S, Mathers C, Rebelo M, et al. Cancer incidence and mortality worldwide: sources, methods and major patterns in GLOBOCAN 2012. Int J Cancer 2015;136:E359-86.

2. Jung KW, Won YJ, Kong HJ, Oh CM, Lee DH, Lee JS. Cancer statistics in Korea: incidence, mortality, survival, and prevalence in 2011. Cancer Res Treat 2014:46:109-23.

3. Verma M. Cancer epidemiology. Methods in molecular biology (Clifton, N.J.) series, 472. New York, Humana Press, 2009.

4. Cogliano VJ, Baan R, Straif K, Grosse Y, Lauby-Secretan B, El Ghissassi F, et al. Preventable exposures associated with human cancers. J Natl Cancer Inst 2011;103:1827-39.

5. World Cancer Research Fund, American Institute for Cancer Research. Food, nutrition, physical activity, and the prevention of cancer: a global perspective. Washington, DC, World Cancer Research Fund/American Institute for Cancer Research, 2007.

6. Doll R, Peto R. Mortality in relation to smoking: 20 years' observations on male British doctors. Br Med J 1976;2:1525-36.

7. Hammond EC, Horn D. Smoking and death rates: report on forty-four months of follow-up of 187,783 men. 2 . Death rates by cause. J Am Med Assoc 1958;166:1294-308.

8. Kahn HA. The Dorn study of smoking and mortality among U.S. veterans: report on eight and one-half years of observation. Natl Cancer Inst Monogr 1966;19:1-125.

9. Rogot E, Murray JL. Smoking and causes of death among U.S. veterans: 16 years of observation. Public Health Rep 1980;95:213-22.

10. Giovannucci E. An updated review of the epidemiological evidence that cigarette smoking increases risk of colorectal cancer. Cancer Epidemiol Biomarkers Prev 2001;10:725-31.

11. Kim HJ, Lee SM, Choi NK, Kim SH, Song HJ, Cho YK, et al. Smoking and colorectal cancer risk in the Korean elderly. J Prev
Med Public Health 2006:39:123-9.

12. Kim DH, Ahn YO, Lee BH, Tsuji E, Kiyohara C, Kono S. Methylenetetrahydrofolate reductase polymorphism, alcohol intake, and risks of colon and rectal cancers in Korea. Cancer Lett 2004:216:199-205.

13. Kim J, Kim DH, Lee BH, Kang SH, Lee HJ, Lim SY, et al. Folate intake and the risk of colorectal cancer in a Korean population. Eur J Clin Nutr 2009;63:1057-64.

14. Lim HJ, Park BJ. Cohort study on the association between alcohol consumption and the risk of colorectal cancer in the Korean elderly. J Prev Med Public Health 2008;41:23-9.

15. Choi SY, Kahyo H. Effect of cigarette smoking and alcohol consumption in the etiology of cancers of the digestive tract. Int J Cancer 1991:49:381-6.

16. Yoo KY, Shin HR, Chang SH, Lee KS, Park SK, Kang D, et al. Korean multi-center cancer cohort study including a biological materials bank (KMCC-I). Asian Pac J Cancer Prev 2002;3:85-92.

17. Korn EL, Graubard BI, Midthune D. Time-to-event analysis of longitudinal follow-up of a survey: choice of the time-scale. Am J Epidemiol 1997;145:72-80.

18. Thiébaut AC, Bénichou J. Choice of time-scale in Cox's model analysis of epidemiologic cohort data: a simulation study. Stat Med 2004:23:3803-20.

19. Forman D, Bray F, Brewster DH, Gombe Mbalawa C, Kohler B, Piñeros $\mathrm{M}$, et al. Cancer incidence in five continents, Vol. X. Lyon: International Agency for Research on Cancer, 2014.

20. Shin A, Joo J, Bak J, Yang HR, Kim J, Park S, et al. Site-specific risk factors for colorectal cancer in a Korean population. PLoS One 2011;6:e23196.

21. Choi SY, Kahyo H. Effect of cigarette smoking and alcohol consumption in the aetiology of cancer of the oral cavity, pharynx and larynx. Int J Epidemiol 1991;20:878-85.

22. Fedirko V, Tramacere I, Bagnardi V, Rota M, Scotti L, Islami F, et al. Alcohol drinking and colorectal cancer risk: an overall and dose-response meta-analysis of published studies. Ann Oncol 2011:22:1958-72.

23. Moskal A, Norat T, Ferrari P, Riboli E. Alcohol intake and colorectal cancer risk: a dose-response meta-analysis of published cohort studies. Int J Cancer 2007;120:664-71.

24. Cho E, Smith-Warner SA, Ritz J, van den Brandt PA, Colditz GA, Folsom AR, et al. Alcohol intake and colorectal cancer: a pooled analysis of 8 cohort studies. Ann Intern Med 2004;140:603-13.

25. Mizoue T, Inoue M, Wakai K, Nagata C, Shimazu T, Tsuji I, et al; Research Group for Development and Evaluation of Cancer Prevention Strategies in Japan. Alcohol drinking and colorectal cancer in Japanese: a pooled analysis of results from five cohort studies. Am J Epidemiol 2008;167:1397-406.

26. Bagnardi V, Rota M, Botteri E, Tramacere I, Islami F, Fedirko V, et al. Light alcohol drinking and cancer: a meta-analysis. Ann Oncol 2013:24:301-8.

27. Jee SH, Samet JM, Ohrr H, Kim JH, Kim IS. Smoking and cancer risk in Korean men and women. Cancer Causes Control 2004;15: 341-8.

28. Botteri E, Iodice S, Bagnardi V, Raimondi S, Lowenfels $A B$, Maisonneuve P. Smoking and colorectal cancer: a meta-analysis. JAMA 2008:300:2765-78.

29. Liang PS, Chen TY, Giovannucci E. Cigarette smoking and colorectal cancer incidence and mortality: systematic review and meta-analysis. Int J Cancer 2009;124:2406-15. 
30. Leufkens AM, Van Duijnhoven FJ, Siersema PD, Boshuizen HC Vrieling A, Agudo A, et al. Cigarette smoking and colorectal cancer risk in the European Prospective Investigation into Cancer and Nutrition study. Clin Gastroenterol Hepatol 2011;9:137-44.
31. Parajuli R, Bjerkaas E, Tverdal A, Selmer R, Le Marchand L, Weiderpass $\mathrm{E}$, et al. The increased risk of colon cancer due to cigarette smoking may be greater in women than men. Cancer Epidemiol Biomarkers Prev 2013:22:862-71. 